Porque o processo de imaginação e inovação não está esgotado, pelo contrário, aplicando-se actualmente e cada vez mais em todas as actividades da vida humana, propusemos aos nossos alunos que fossem à conquista do conhecimento (que a passividade não é aliada do mesmo), e que, através da imaginação, ousassem inovar.

Neste IV Encontro, mostrámos a quem nos visitou o processo imaginação-criatividade-conhecimento-inovação e o resultado do mesmo. Assim, nos dias 25 , 26 e 27 de Março, o Instituto D. João $\mathrm{V}$ dinamizou um vasto conjunto de actividades dirigidas à própria comunidade escolar, mas também aos alunos do $1 .^{\circ}$ Ciclo da sua área pedagógica.

Do programa, constou a realização de exposições permanentes, dramatizações, concursos em torno da língua portuguesa, acções de formação/ateliês, actividades físicas, sessões de cinema e outras actividades científicas e culturais, nomeadamente a apresentação pública de diversas Áreas de Projecto do $12 .^{\circ}$ ano - no âmbito da Química, da Física e da Biologia - a Feira do Livro e o encontro com um escritor.

A Imaginação e Inovação na Química e na Física, foi o título da exposição interactiva preparada e apresentada por alunos dos $10 .^{\circ}$ e $12 .^{\circ}$ anos, no Laboratório de Química. Nela, os alunos tiveram a oportunidade de relacionar, com a Química e com a Física, algumas das actividades que se fazem no dia-a-dia.

Foi feita a apresentação pública dos projectos desenvolvidos no âmbito das Áreas de Projecto do $12 .^{\circ}$ ano. Produção de biogás e de fertilizantes a partir de excrementos de suínos e divulgação deste método de tratamento de efluentes de suiniculturas; lavagem do biogás com um lavador de gases construído pelos alunos;

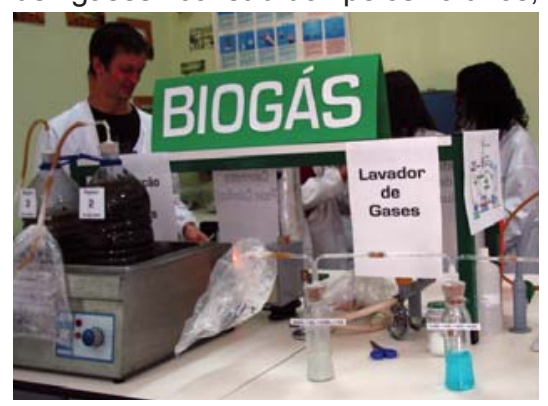

construção de um calorímetro para determinação de poderes caloríficos de vários gases (butano e biogás); determinação da massa volúmica do biogás.

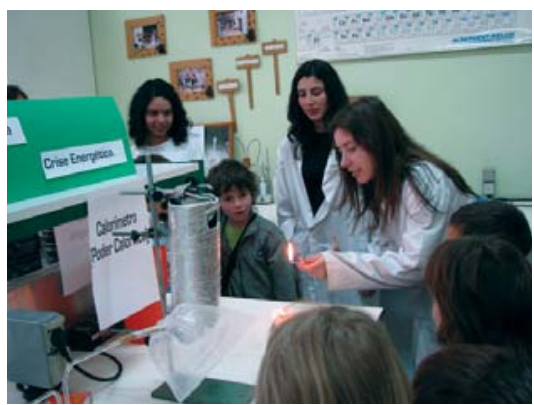

Divulgação do estudo sobre o percurso do leite, desde que sai da ordenha até chegar ao mercado; divulgação de alguns processos fisíco-químicos e bioquímicos associados à produção de derivados do leite; produção de vários tipos de iogurtes e de leites fermentados, de manteiga, de queijo brunost, de queijo fresco, de Kefir, de iogurteiras/ queijeiras com materiais reutilizados; realização de diversas análises químicas ao leite; construção do modelo molecular da lactose.

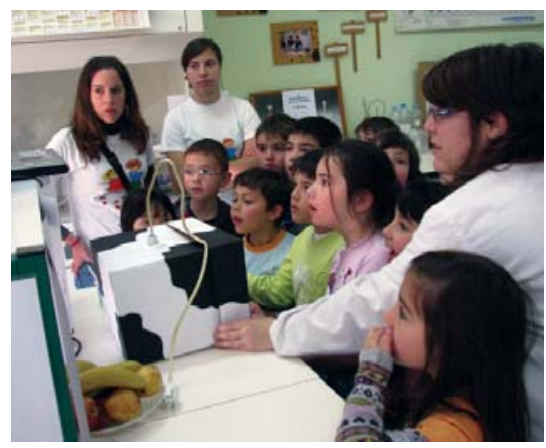

Estudo da composição de alguns cosméticos; divulgação de algumas reacções químicas e processos físicos e químicos usados na produção dos cosméticos; produção de uma linha de cosméticos naturais constituída por óleos essenciais de citrinos, cremes hidratantes, máscaras hidratantes, bálsamos para os lábios, sabonetes, loções faciais, loções para homem, cera depilatória...

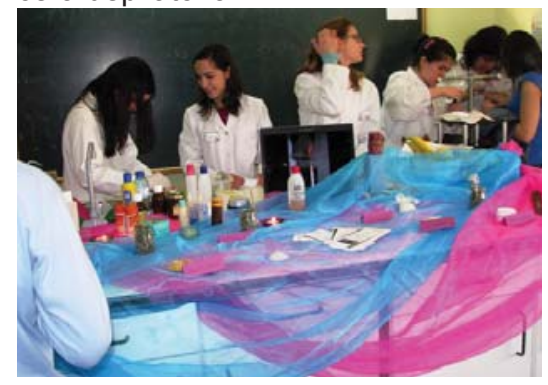

Produção de biodiesel a partir de óleos alimentares; divulgação das vantagens e inconvenientes da produção intensiva de biodiesel; estudo do rendimento da produção de biodiesel e glicerol; determinação das características do biodiesel tais como a densidade relativa, poder calorífico, flash point, ponto de congelação.

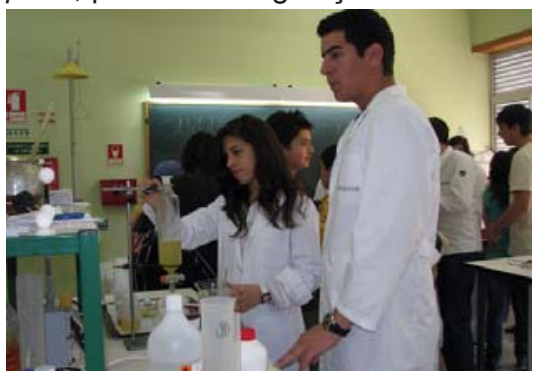

Produção de licores, divulgação de alguns dos efeitos das bebidas alcoólicas na sociedade, no cérebro e noutros órgãos do corpo humano; determinação da percentagem de álcool em várias bebidas por destilação fraccionada; estudo de algumas reacções químicas relacionadas com a produção de bebidas alcoólicas, nomeadamente a fermentação alcoólica; simulação do "Teste do Balão", por reacção do etanol com dicromato de potássio, para identificar pessoas alcoolizadas.

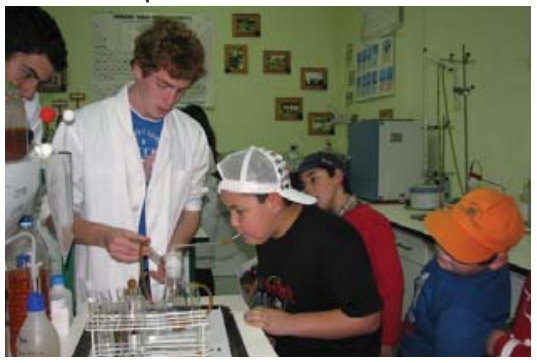

Os alunos do $10 .^{\circ}$ ano, do curso de Ciências e Tecnologia, prepararam também algumas actividades experimentais para os visitantes tais como: Princípios da utilização das fibras ópticas; Demonstração do princípio de Arquimedes; Efeito da variação da pressão sobre o volume de uma mistura de gases; Transformação de um sinal sonoro num sinal eléctrico e comparação de sons puros com sons complexos.

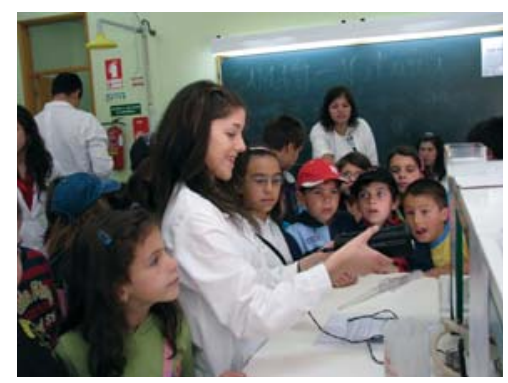




\section{Actualidade Científica}

Catalisador Sintético Mimetiza o Processamento Natural de HidroGÉNIO

Através da construção de um modelo de centro activo característico de uma enzima natural, uma equipa de Químicos da Universidade de Illinois obteve uma forma de compreender o processamento natural de hidrogénio.

Os investigadores há muito se interrogam sobre a capacidade da Natureza em usar núcleos comuns e baratos como ferro, níquel e enxofre com um desempenho catalítico semelhante ao observado em metais raros e muito mais dispendiosos.

Particularmente, destaca-se o caso de duas enzimas - hidrogenase ferro-ferro e hidrogenase níquel-ferro - que funcionam como processadores de hidrogénio, da mesma forma que, por exemplo, a platina.

Thomas B. Rauchfuss, Químico da Universidade de Illinois afirma que "A Natureza baseia a sua pró- pria economia de hidrogénio numa complexa e elaborada estrutura.

O nosso trabalho consiste em descodificar o processo e gerar simulações do centro activo catalítico que interage com o substrato de hidrogénio".

O modelo assim construído de um complexo níquel-ferro é pioneiro na inclusão de um ligando de ponte de hidreto, que se revela um componente essencial do catalisador.

"Através de uma melhor compreensão do mecanismo de funcionamento do centro activo de níquel-ferro da hidrogenase, pretende-se desenvolver novos catalisadores sintéticos para diferentes aplicações", afirma o estudante de graduação Bryan E. Barton, principal autor do estudo.

O estudante de graduação e co-autor Matthew Whaley acrescenta "O estudo de hidrogenases oferece um grande potencial no contexto do desenvolvimento da economia de hidrogénio, nas áreas da energia verde e das células de biocombustível.
A construção deste modelo que contém um ligando de hidreto demonstrou que o comportamento destes catalisadores naturais pode ser compreendido e optimizado.

A equipa de investigação (que inclui a cristalógrafa Danielle L. Gray) apresentou o seu trabalho no Journal of the American Chemical Society.

(adaptado de ScienceDaily www.sciencedaily.com/ releases/2009/05/090518121002. htm, acedido em 24/05/2009)

Paulo Brito
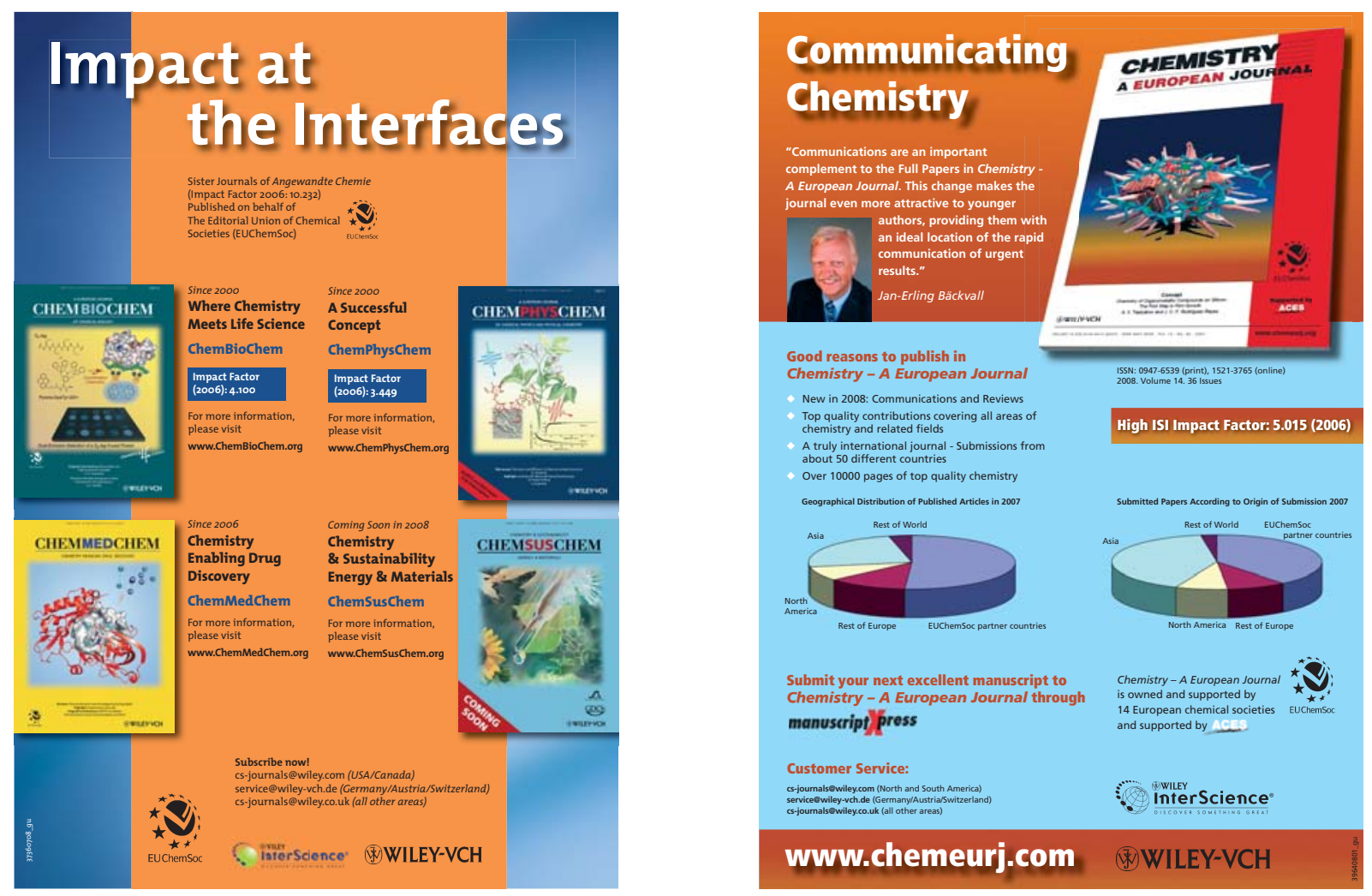